\title{
Eligibility and willingness to donate blood in men who have (had) sex with men
}

Citation for published version (APA):

Romeijn, B., Merz, E-M., Kok, G., de Kort, W., \& van Dongen, A. (2018). Eligibility and willingness to donate blood in men who have (had) sex with men. Transfusion, 58(3), 710-717. https://doi.org/10.1111/trf.14469

Document status and date:

Published: 01/03/2018

DOI:

10.1111/trf.14469

Document Version:

Publisher's PDF, also known as Version of record

Document license:

Taverne

Please check the document version of this publication:

- A submitted manuscript is the version of the article upon submission and before peer-review. There can be important differences between the submitted version and the official published version of record.

People interested in the research are advised to contact the author for the final version of the publication, or visit the DOI to the publisher's website.

- The final author version and the galley proof are versions of the publication after peer review.

- The final published version features the final layout of the paper including the volume, issue and page numbers.

Link to publication

\footnotetext{
General rights rights.

- You may freely distribute the URL identifying the publication in the public portal. please follow below link for the End User Agreement:

www.umlib.nl/taverne-license

Take down policy

If you believe that this document breaches copyright please contact us at:

repository@maastrichtuniversity.nl

providing details and we will investigate your claim.
}

Copyright and moral rights for the publications made accessible in the public portal are retained by the authors and/or other copyright owners and it is a condition of accessing publications that users recognise and abide by the legal requirements associated with these

- Users may download and print one copy of any publication from the public portal for the purpose of private study or research.

- You may not further distribute the material or use it for any profit-making activity or commercial gain

If the publication is distributed under the terms of Article $25 \mathrm{fa}$ of the Dutch Copyright Act, indicated by the "Taverne" license above, 


\title{
Eligibility and willingness to donate blood in men who have (had) sex with men
}

\author{
Bas Romeijn, ${ }^{1}$ Eva-Maria Merz, ${ }^{1,2}$ Gerjo Kok, ${ }^{3}$ Wim de Kort, ${ }^{1,4}$ and Anne van Dongen ${ }^{5}$
}

BACKGROUND: Several countries have changed, or are reevaluating, their blood donor policies for men who have had sex with men (MSM). Changing policies has consequences for donor recruitment and the donor pool. In this study, we investigated whether MSM are eligible and willing to donate blood.

STUDY DESIGN AND METHODS: Members of a research panel $(n=4422)$ in the Netherlands were invited to participate in an online survey. We asked questions about male-to-male sex and risk behavior that are also asked during the predonation screening of a blood donor. Furthermore, we asked questions about willingness to donate.

RESULTS: The total response rate was $60 \%$ ( $n=2654$ ). Of MSM nondonors $(n=230), 32.2 \%$ would be eligible to donate under a 12-month deferral policy, according to their reported risk history and last male-tomale sex. In other scenarios, $42.6 \%$ (4-month deferral), $38.7 \%$ (6-month deferral), and $18.7 \%$ (5-year deferral) would be eligible to donate. When not taking their last male-to-male sex into account $(n=203), 47.8 \%$ of MSM reported a moderate or high willingness to donate.

CONCLUSION: A 12-month deferral after last male-tomale sex is a commonly used criterion by blood services. Approximately one-third of the MSM in our study would be eligible to donate under this deferral policy. Higher proportions of MSM would be eligible to donate in shorter deferral scenarios. Almost half of MSM are willing to donate blood. Targeting MSM by donor recruitment campaigns could therefore prove fruitful.
$\mathrm{T}$ he HIV/AIDS epidemic in the 1980s disproportionately affected men who have had sex with men (MSM). ${ }^{1}$ At the time of the outbreak of the epidemic, HIV blood testing was not available, while the virus has a high risk of being transmitted through transfusion. To prevent transfusion-transmitted infections, in particular HIV, many countries (permanently) excluded MSM from donating blood or blood components. ${ }^{2}$ Not long after implementation of the ban, the first HIV antibody test was licensed and, years later, nucleic acid amplification testing (NAT) was introduced. ${ }^{3}$ Both methods have helped to significantly reduce the risk of transfusion-transmitted infections.

Improved testing methods and increased knowledge and awareness regarding HIV and other infectious diseases have led to reevaluations of donor policies for MSM worldwide. Several Western countries including the United States, ${ }^{4}$ the United Kingdom, ${ }^{5}$ and the Netherlands ${ }^{6}$ have

ABBREVIATIONS: IDU(s) = intravenous drug user(s); MSM = men who have had sex with men; PES = paid drugs or money in exchange for sex; RES = received drugs or money in exchange for sex; SHIV = sex with a person infected with HIV; SIDU = sex with an intravenous drug user.

From the ${ }^{1}$ Department of Donor Studies, Sanquin Research; and the ${ }^{2}$ Department of Sociology, Vrije Universiteit, Amsterdam, the Netherlands; the ${ }^{3}$ Department of Applied Social Psychology, Maastricht University, Maastricht, the Netherlands; the ${ }^{4}$ Department of Social Medicine, Academic Medical Centre, Amsterdam, the Netherlands; and the ${ }^{5}$ School of Psychology, University of New South Wales, Sydney, Australia.

Address reprint requests to: Bas Romeijn, Department of Donor Studies, Sanquin Research, P.O. Box 9137, 1006 AC Amsterdam, the Netherlands; e-mail: b.romeijn@sanquin.nl. Received for publication July 3, 2017; revision received November 13, 2017; and accepted November 17, 2017.

doi:10.1111/trf.14469

(C) $2017 \mathrm{AABB}$

TRANSFUSION 2018;58;710-717 
changed their blood donor policies for MSM to a 1-year deferral after the last male-to-male sex in recent years. Study results show that the observed HIV-positive cases in male donors in countries that have implemented a temporary deferral (Australia, United Kingdom, Canada) roughly remain at the same levels as before the policy change. ${ }^{7,8}$ These results are not in line with predictions from studies where the change in HIV rate in changing deferral criteria for MSM has been mathematically modeled ${ }^{9-14}$ and suggest that these models were overly conservative. At present, MSM are still permanently excluded from blood donation in several countries, although it is likely that more blood services will implement a less strict deferral policy for MSM in the future.

Changing deferral criteria can have consequences for donor recruitment and the composition of the donor pool. MSM will be allowed to donate if no longer permanently excluded. In addition, MSM who were permanently deferred in the past can resume their donor career. Insight into the proportion of nondonors that would potentially be eligible and willing to donate in various deferral scenarios may provide clues for donor base management. Previous research in the United States has assessed to what extent MSM would be eligible and interested in donating blood if the policy were to change, ${ }^{15}$ but for the Netherlands limited data are available. We performed a survey to investigate the situation in the Netherlands.

We conducted an online survey in a population consisting of MSM, non-MSM, and female nondonors. We asked about (sexual) risk behavior relevant to blood donation and then assessed what this would mean for their eligibility to donate given various (hypothetical) deferral periods. We also examined participants' willingness to donate and whether this differed between groups of MSM, non-MSM, women, and according to age, education, and time since last male-to-male sex. This study was performed simultaneously with a study in the Dutch donor population in which we determined donor compliance with the permanent deferral for MSM in the Netherlands. ${ }^{16}$ Both studies were used to provide scientific support for lifting the permanent ban on blood donation for MSM in the Netherlands.

\section{MATERIALS AND METHODS}

\section{Participants and procedures}

The Flycatcher panel (http://www.flycatcher.eu) consists of 16,000 members more than 12 years old. The panel is ISO 20252 and 26362 certified and therefore meets all quality requirements for access panels to conduct scientific, opinion, and market research. Panel members receive points to spend on gift certificates after completing a survey. For this study, we developed a questionnaire format that Flycatcher incorporated into their online questionnaire software.

In the first batch of invitations sent out on October 30, 2014, Flycatcher invited 597 panel members aged between 18 and 70 years old (the age limits for donating blood in the Netherlands) to participate in an online survey. This sample of invitees was stratified for sex, age, educational level, and region and was representative of the Dutch general population according to the most recent data of Statistics Netherlands. Furthermore, to determine if the respondents were representative of the Dutch population, a calibration instrument developed by the Center for Information-Based Decision Making \& Marketing Research in collaboration with Statistics Netherlands was used. Automatic reminders were sent out to invitees who had not responded on November 3, 2014.

Additionally, Flycatcher sent an invitation to all remaining male panel members aged between 18 and 70 years old $(\mathrm{n}=3825)$ on November 10,2014 , to obtain a sufficient sample of MSM. Invitees in this second batch of invitations did not receive a reminder as a sufficient number of MSM had already responded after the initial invitation. In total, 4422 panel members were invited in the first and second batches. At the time of this study MSM were permanently excluded from donating blood or blood components in the Netherlands. Both the Ethical Advisory Council of Sanquin and the Research Ethics Board of the Faculty of Psychology and Neuroscience of Maastricht University (ECP-05-09-2012) approved this survey.

\section{Measures}

The questions that were used in this survey can be found in Appendix S1 (available as supporting information in the online version of this paper). All participants were asked if they had donated blood in the past and if they were currently registered as a donor at Sanquin. We used questions based on those in the Dutch Donor Health Questionnaire to ascertain whether participants had a history of risk behavior which is assessed during the predonation screening. The Donor Health Questionnaire is employed in the donor screening procedure before every donation attempt to identify donors who are (temporarily) not eligible. Thus participants were asked whether they had ever injected drugs (IDUs) or had ever received drugs or money in exchange for sex (RES). Donors are permanently excluded from donation in the Netherlands if they report a history of IDU or RES. We also asked if respondents ever had sexual contact which they paid for with drugs or money (PES), had sex with an intravenous drug user (SIDU), or had sex with an HIV-infected person (SHIV). Donors who report PES, SIDU, or SHIV are deferred from donation for 12 months according to the Dutch donor selection policy. 
We asked male respondents whether they had ever had male-to-male sex according to the following definition: "With male-to-male sex we mean: anal sex (contact between penis and anus) or oral sex (mouth or tongue on someone's penis or anus) with or without a condom. This also applies to a situation where both men and women are present." Respondents who reported a history of risk behavior were asked to indicate the time interval since the last occurrence of the behavior.

\section{Willingness to donate}

We measured willingness to donate using two items measured on a five-point Likert-scale ranging from "completely disagree" to "completely agree": "I would like to donate blood" and "If I am allowed to donate blood according to the donor eligibility criteria, I would register as a donor." We combined the score of these two items into one mean score for willingness to donate. We performed a median split on willingness to donate (median, 3.00) to define no, low versus moderate, or high willingness. Mean scores up to three were considered as a low willingness to donate. Mean scores above three were considered as a moderate or high willingness to donate.

\section{Statistical analyses}

We used computer software (SPSS Statistics for Windows, Version 21.0, IBM Corp.) for analyses. Demographics and risk behavior were assessed using descriptive statistics. Eligibility assessments for different deferral scenarios (4month, 6-month, 12-month, and 5-year deferral policies) were restricted to MSM and performed using descriptive statistics. We used t tests for independent samples to assess differences in mean scores for willingness to donate with participants' sex (male or female) and past donor status (yes or no) as independent variables. To calculate mean differences in scores for willingness to donate with group (MSM, non-MSM, and female), age category (18-35, 36-55, and 56-69 years old), and educational level (low, medium, high) as independent variables, we used oneway analysis of variance (ANOVA) and post hoc procedures with Hochberg's GT2 tests because of unequal sample sizes. Finally, we conducted a multivariate linear regression analysis of the association between willingness to donate and group (i.e., MSM, non-MSM, and females), age category, educational level, and past donor status.

\section{RESULTS}

After removal by Flycatcher of invalid answering patterns ( $\mathrm{n}=10$ ) and incomplete surveys $(\mathrm{n}=62), 2654$ participants completed the questionnaire (total response, $60 \%$ ). Initially, the response rate for the first batch of invitations was $34.8 \%(n=209)$. The response increased to $51 \%$ ( $\mathrm{n}=305,153$ males and 152 females) after sending out a reminder. For the second batch of invitations the response rate was $61 \%$. These are satisfactory response rates for the Netherlands, as they tend to be lower than in other Western industrialized countries. ${ }^{17}$ A total of 255 respondents, including eight MSM who should not have been permitted to donate at the time of the study, reported that they were registered as a donor at Sanquin. We excluded those participants who were currently registered as blood donors, leaving 2399 respondents for further analyses.

\section{Demographics, donor history, and male-to-male sex}

Descriptive statistics for the three groups (MSM, nonMSM, and women) can be found in Table 1. Of male respondents ( $\mathrm{n}=2262), 230(10.2 \%)$ reported ever having had sex with a man. Almost one-quarter (24.3\%) of MSM and non-MSM (23.8\%) reported that they ever had donated blood in the past, compared to a lower percentage of women (13.1\%). Respondents reported a mean age of 48.66 years (range, 18-69 years; SD, 13.46 years). More than half of MSM and non-MSM (both groups 50.9\%) reported a high educational level (a higher vocational or university education), compared to $25.5 \%$ of female respondents.

\section{Risk behavior}

Table 1 shows reported risk behavior for MSM, non-MSM, and female respondents. The majority of respondents (91.9\%) reported no history of risk behavior. In total, 12 respondents $(0.5 \%)$ reported risk behavior (IDU or RES) constituting a reason to permanently exclude them from donation. In general, PES was the most frequently reported risk behavior among all respondents $(n=130$, $5.4 \%$ ). Of MSM, 72\% reported that they had no history of risk behavior (other than male-to-male sex); 20 MSM $(8.7 \%)$ reported having engaged in risk behavior that would defer them for a year from donation (e.g., PES, SIDU, SHIV). Approximately one-third ( $\mathrm{n}=79,34.3 \%$ ) of MSM reported that their last male-to-male sex was more than 1 year ago (Table 1), but the majority (49.1\%) reported that they had recently (less than 4 months ago) had sex with a man.

\section{Eligibility of MSM}

The flow chart in Fig. 1 shows the proportions of MSM that would potentially be eligible to donate under various deferral scenarios according to their reported history of risk behavior. If we do not take male-to-male sex into account, 203 MSM (88.3\%) would be eligible to donate according to their reported status regarding IDU, RES, PES, SIDU, or SHIV. In a 4-month deferral scenario, $42.6 \%$ ( $\mathrm{n}=98$ ) of MSM would be eligible to donate and in a 6month deferral policy $38.7 \%(n=89)$ would be eligible. Furthermore, approximately one-third of MSM $(32.2 \%$, 


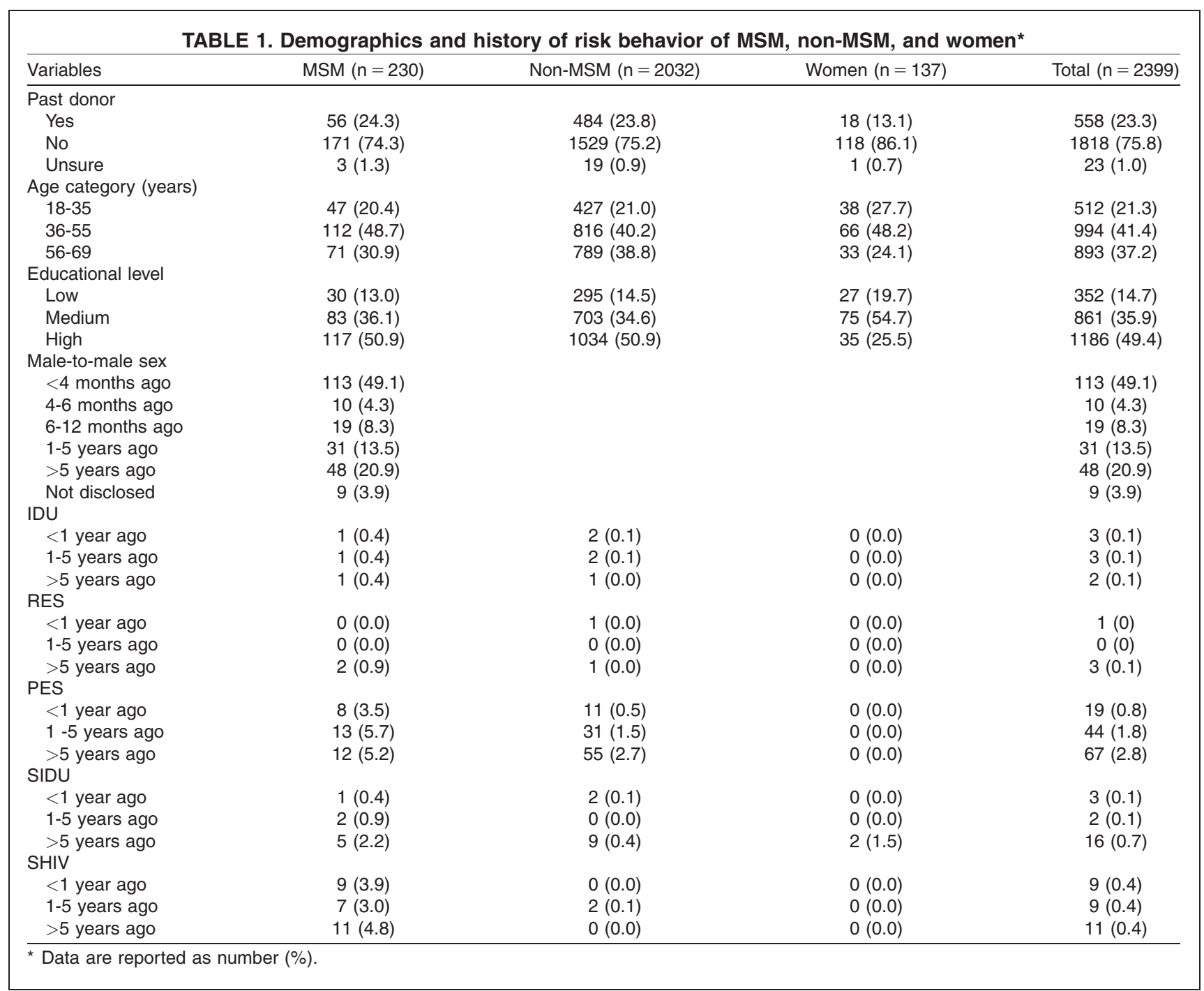

$\mathrm{n}=74$ ) would potentially be eligible to donate under a 1year deferral policy, and 18.7\% ( $n=43)$ of MSM would be eligible under a 5-year deferral policy.

\section{Willingness to donate}

First, we assessed willingness to donate among MSM, non-MSM, and female respondents who were eligible to donate according to their reported risk history. For MSM, we did not take last male-to-male sex into account ( $n=203)$. Almost half of eligible MSM $(47.8 \%, n=97)$ reported a moderate or high willingness to donate. No or low willingness to donate was reported by $41.9 \%(n=85)$ of MSM. Of eligible non-MSM male $(n=1998)$ and female respondents, respectively, $31.2 \%(\mathrm{n}=624)$ and $38.5 \%$ $(\mathrm{n}=52$ ) indicated a moderate or high willingness to donate, whereas $54.7 \%(\mathrm{n}=1093)$ of non-MSM males and $45.2 \%(n=61)$ of females indicated no or low willingness to donate. Second, we examined if there were differences in mean scores on willingness to donate between these groups. The results of the ANOVA with post hoc procedures and $\mathrm{t}$ tests are presented in Table 2. The mean $( \pm \mathrm{SD})$ score for willingness to donate for all respondents was 3.05 ( \pm 0.97 ). Table 3 shows the results of a final multivariate linear regression model with willingness to donate as the dependent variable and age category, group (i.e., MSM, non-MSM, and females), past donor status, and educational level as independent variables. Significant effects were found for being MSM or female (compared to non-MSM), age category 36-55 years (compared to 56-69 years), and a medium educational level (compared to higher education) on willingness to donate.

\section{DISCUSSION}

Since December 2015, men in the Netherlands have been allowed to donate if they have not had sex with other men for at least 12 months. This study was designed to gain insight into the proportions of MSM that might be eligible 


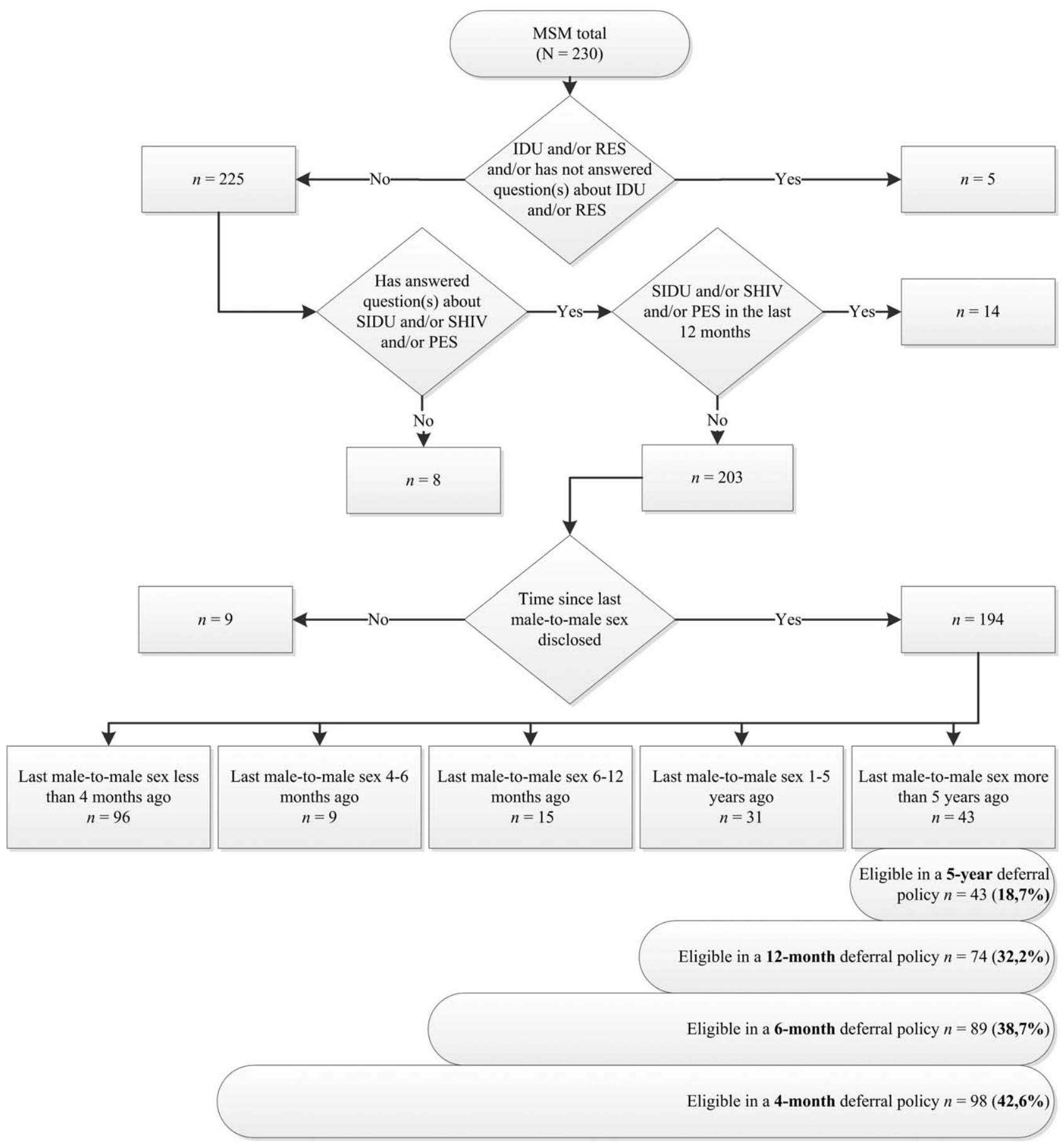

Fig. 1. Eligibility of MSM to donate in various deferral scenarios according to their reported risk behavior.

to donate in various deferral scenarios and whether they are willing to donate. In our study, performed when MSM were still permanently excluded from blood donation in the Netherlands, we found that almost one-third of MSM would be potentially eligible to donate in a 12-month deferral scenario according to their reported risk history. In shorter deferral scenarios, such as a 4-month deferral $(42.6 \%)$ and a 6-month deferral $(38.7 \%)$ after last male-to- male sex, somewhat higher proportions of MSM would be eligible.

We found higher proportions of MSM potentially eligible to donate than those found in a study performed in the United States, where only $2.3 \%$ (under a 12-month deferral policy) and $10.1 \%$ (in 6-month deferral policy) of MSM might be eligible to donate. ${ }^{15}$ An explanation for this result could be that in our study population more 


\begin{tabular}{|c|c|c|c|}
\hline \multicolumn{4}{|c|}{$\begin{array}{l}\text { TABLE 2. Differences in scores on willingness to } \\
\text { donate }\end{array}$} \\
\hline \multirow[b]{2}{*}{ Variables } & \multicolumn{3}{|c|}{ Willingness to donate } \\
\hline & Number & Mean $( \pm S D)$ & F/t value \\
\hline Total & 2068 & $3.05( \pm 0.97)$ & \\
\hline Sex & & & -1.33 \\
\hline Male & 1954 & $3.04( \pm 0.96)$ & \\
\hline Female & 114 & $3.17( \pm 0.99)$ & \\
\hline Past donor & & & $12.51 \dagger$ \\
\hline No & 1529 & $2.89( \pm 0.92)$ & \\
\hline Yes & 520 & $3.49( \pm 0.96)$ & \\
\hline $\begin{array}{l}\text { Time since last } \\
\text { male-to-male sex }\end{array}$ & & & $-2.10^{*}$ \\
\hline$<4$ months ago & 103 & $3.51( \pm 1.10)$ & \\
\hline$>4$ months ago & 97 & $3.20( \pm 1.11)$ & \\
\hline Age category (years) & & & $9.49+\S$ \\
\hline $18-35(1)$ & 427 & $3.04( \pm 0.96)$ & \\
\hline $36-55(2)$ & 846 & $2.95( \pm 0.97)$ & \\
\hline $56-69(3)$ & 795 & $3.16( \pm 0.96)$ & \\
\hline Group & & & 13.83†‡ \\
\hline Non-MSM (1) & 1746 & $3.00( \pm 0.95)$ & \\
\hline MSM (2) & 208 & $3.36( \pm 1.06)$ & \\
\hline Women (3) & 114 & $3.17( \pm 0.99)$ & \\
\hline Educational level & & & $5.74 \star \S$ \\
\hline Low (1) & 283 & $3.07( \pm 0.97)$ & \\
\hline Medium (2) & 744 & $3.14( \pm 0.98)$ & \\
\hline High (3) & 1014 & $2.98( \pm 0.95)$ & \\
\hline \multicolumn{4}{|c|}{$\begin{array}{l}\text { ^ } \mathrm{p}<0.05 \text {. } \\
\dagger \mathrm{p}<0.001 \text {. } \\
\text { † } \mathrm{p}<0.05 \text { for mean score difference between (1) and (2) } \\
\text { according to post hoc comparisons using Hochberg's GT2 } \\
\text { test. } \\
\S \mathrm{p}<0.05 \text { for mean score difference between (2) and (3) } \\
\text { according to post hoc comparisons using Hochberg's GT2 } \\
\text { test. }\end{array}$} \\
\hline
\end{tabular}

than one-third of MSM reported that they were not currently sexually active with other men at that time (e.g., their reported last male-to-male sex was more than 12 months ago). In our compliance study in the Dutch donor population we found a comparable percentage of men who reported not being sexually active (e.g., they reported having had sex with a man just once and a long time ago). ${ }^{16}$ In the US study respondents were recruited at settings primarily visited by men who identify themselves as MSM and where the majority of participants reported a homosexual or bisexual orientation. We did not ask what our respondents' self-reported sexual orientation was, only if they had man-to-man sex, and it is likely that we included men who do not identify themselves as MSM, but represented men who experimented with male-tomale sex on a rare occasion in the past, or men who were sexually abused by other men in the past. Another possible explanation could be that in the US study additional questions were asked to ascertain a history of HIV, hepatitis, gonorrhea, or syphilis and what this means for participants' eligibility, which could mean that more MSM would be ineligible.

In our survey, almost half of eligible MSM expressed willingness to donate. This proportion is significantly

\begin{tabular}{|c|c|c|c|}
\hline \multicolumn{4}{|c|}{$\begin{array}{l}\text { TABLE 3. Multivariate linear regression model of } \\
\text { willingness to donate on age category, group, past } \\
\text { donor status, and educational level }(n=2049)\end{array}$} \\
\hline \multirow[b]{2}{*}{ Variables } & \multicolumn{3}{|c|}{ Willingness to donate } \\
\hline & B & SE (B) & $\beta$ \\
\hline \multicolumn{4}{|c|}{ Age category (years) } \\
\hline $18-35$ & 0.07 & 0.06 & 0.03 \\
\hline $36-55$ & $-0.12^{*}$ & 0.05 & -0.06 \\
\hline $56-69$ & Ref. & Ref. & \\
\hline \multicolumn{4}{|l|}{ Group } \\
\hline Non-MSM & Ref. & Ref. & \\
\hline MSM & $0.36 \dagger$ & 0.07 & 0.11 \\
\hline Women & $0.21^{*}$ & 0.09 & 0.05 \\
\hline \multicolumn{4}{|l|}{ Past donor } \\
\hline No & Ref. & Ref. & \\
\hline Yes & $0.60 \dagger$ & 0.05 & 0.27 \\
\hline \multicolumn{4}{|c|}{ Educational level } \\
\hline Low & 0.07 & 0.06 & 0.02 \\
\hline Medium & $0.12 \dagger$ & 0.05 & 0.06 \\
\hline High & Ref. & Ref. & \\
\hline Intercept & 2.83 & 0.05 & \\
\hline $\mathrm{R}^{2}(\%)$ & $9 \%$ & & \\
\hline $\begin{array}{l}{ }^{*} p<0.05 . \\
+p<0.001 .\end{array}$ & & & \\
\hline
\end{tabular}

higher compared to non-MSM and females, a difference that was also seen in the multivariate analysis. It is unlikely, however, that all these respondents will actually register as a donor in the future, as expressing a willingness to perform a particular behavior does not always lead to the behavior actually being performed. ${ }^{18} \mathrm{~A}$ possible explanation for the higher willingness to donate in MSM may be that they were not allowed to donate at the time of our study and may therefore be motivated to donate as well. Another explanation might be that we excluded registered donors from our analyses. Non-MSM and women are allowed to donate; therefore, it is possible that a proportion of willing individuals are already donating, which is not the case for MSM.

Belanger and colleagues ${ }^{15}$ found that $77.3 \%$ of respondents were willing to donate blood if the permanent ban was lifted. In another study performed among a convenience sample of MSM in the United States, $85.9 \%$ of the participants reported that they were willing to donate blood. ${ }^{19}$ In both studies in the United States, participants were recruited at venues frequented by MSM where participants could have been distracted during completion of the questionnaire or where social desirability could have influenced the result. ${ }^{19}$ Questions about risk behavior and male-to-male sex may be perceived as sensitive, and respondents could be prone to conceal certain behavior and answer the questions in a socially desirable way. Participants in our study were given the opportunity to answer the questions in a private setting and therefore may have been more inclined to disclose sensitive information as they completed the questionnaire online. 
Our study has some limitations. We did not ask participants to indicate all behavior that is assessed during the predonation screening. Therefore, it is possible that higher numbers of MSM might be ineligible for blood donation. Another limitation is that we do not know if participants who reported male-to-male sex are representative for the Dutch MSM population. For example, we found that almost one-quarter of MSM reported being registered as a donor in the past. Former donors might be overrepresented in the MSM group, since the permanent deferral had been in place since the 1980s. On the other hand, the relatively large proportion of former donors in the MSM group could also represent men who had their male-to-male sex after having donated a few times. MSM who donated in the past were excluded at a certain point and thus could be motivated to respond to our questionnaire and express their opinions regarding this subject. This may also partly explain the difference in response rates between the two batches. The response percentage of the first batch was $51 \%$ after sending a reminder. In Batch 2 a response rate of $61 \%$ had already been reached after the initial invitation, without sending a reminder. Only male respondents were invited in the second batch and may therefore contain a relatively large proportion of MSM (who were registered as a donor in the past) who were eager to respond to this questionnaire. Additionally, it is also unclear if our findings may translate to other countries. Our data rely on self-reporting and therefore may be biased. Future studies that aim to assess eligibility of MSM to donate blood should focus on assessing all risk behavior relevant to blood donation. Moreover, the mean score differences and effects found for willingness to donate according to group (i.e., non-MSM, MSM, and females), age category, and educational level were significant, albeit relatively small. More research is needed to confirm these results.

Our study has several practical implications. The Dutch donor population is aging, and it is particularly difficult to recruit (young) male blood donors. MSM could potentially be targeted by donor recruitment campaigns to contribute to the donor pool in the future. Respondents who reported remote male-to-male sexual contact (e.g., more than 12 months ago) may be available for donation. Another group that could be targeted are the ex-donors (one-quarter of our study population). Our findings suggest that ex-donors are more willing to donate than participants who have not been registered as a donor before. Ex-donors could therefore be approached and asked to reregister as a donor.

However, compliance with donor selection criteria (i.e., whether the donor accurately reports past behavior during the donor selection screening) remains crucial. Interviews with Dutch repeat donors revealed that $28 \%$ (76/272) of the transfusion-transmitted infection-positive cases were noncompliant during the donor screening process. $^{20}$ Some MSM in our study reported having engaged in risk behavior relevant to donation. Therefore, the rationale behind deferral criteria, the limitations of blood screening methods, and the importance of compliance with donor selection criteria have to be thoroughly explained to (new) donors.

\section{CONFLICT OF INTEREST}

The authors have disclosed no conflicts of interest.

\section{REFERENCES}

1. Jaffe HW, Valdiserri RO, De Cock KM. The reemerging HIV/ AIDS epidemic in men who have sex with men. JAMA 2007; 298:2412-4.

2. Wilson K, Atkinson K, Keelan J. Three decades of MSM donor deferral policies. What have we learned? Int J Infect Dis 2014;18:1-3.

3. Roth WK, Busch MP, Schuller A, et al. International survey on NAT testing of blood donations: expanding implementation and yield from 1999 to 2009. Vox Sang 2012;102: 82-90.

4. FDA news release. FDA updates blood donor deferral policy to reflect the most current scientific evidence and continue to ensure the safety of the U.S. blood supply [Internet]. Silver Spring (MD): U.S. Food and Drug Administration; 2015 [cited 2016 Dec 1]. Available from: https://www.fda.gov/ newsevents/newsroom/pressannouncements/ucm478031. htm.

5. Press release. Lifetime blood donation ban lifted for men who have had sex with men [Internet]. London: Department of Health; 2011 [cited 2016 Dec 1]. Available from: https:// www.gov.uk/government/news/lifetime-blood-donationban-lifted-for-men-who-have-had-sex-with-men.

6. Schippers EI. Standpunt rapport MSM \& Bloeddonatie [Internet]. The Hague: Rijksoverheid; 2015 [cited 2016 Dec 1]. Available from: https://www.rijksoverheid.nl/documenten/kamerstukken/2015/10/28/kamerbrief-over-hetdonorselectiebeleid-voor-msm.

7. Germain M. The risk of allowing blood donation from men having sex with men after a temporary deferral: predictions versus reality. Transfusion 2016;56:1603-7.

8. O'Brien SF, Osmond L, Fan W, et al. Impact of a 5-year deferral from blood donation for men who have sex with men. Transfusion 2016;56(6 Pt 2):1598-602.

9. Anderson SA, Yang H, Gallagher LM, et al. Quantitative estimate of the risks and benefits of possible alternative blood donor deferral strategies for men who have had sex with men. Transfusion 2009;49:1102-14.

10. Davison KL, Conti S, Brailsford SR. The risk of transfusiontransmitted HIV from blood donations of men who have sex with men, 12 months after last sex with a man: 2005- 
2007 estimates from England and Wales. Vox Sang 2013; 105:85-8.

11. Germain M, Remis RS, Delage G. The risks and benefits of accepting men who have had sex with men as blood donors. Transfusion 2003;43:25-33.

12. Soldan K, Sinka K. Evaluation of the de-selection of men who have had sex with men from blood donation in England. Vox Sang 2003;84:265-73.

13. Davison KL, Brant LJ, Presanis AM, et al. A re-evaluation of the risk of transfusion-transmitted HIV prevented by the exclusion of men who have sex with men from blood donation in England and Wales, 2005-2007. Vox Sang 2011;101: 291-302.

14. Germain M, Robillard P, Delage G, et al. Allowing blood donation from men who had sex with men more than 5 years ago: a model to evaluate the impact on transfusion safety in Canada. Vox Sang 2014;106: 372-5.

15. Belanger GA, McFarland W, Raymond HF, et al. If the permanent deferral were lifted would men who have sex with men want to donate blood, and if so, who would be eligible? Transfusion 2013;53:2729-33.
16. Romeijn B, van Dongen A, Kok G. Reasons for noncompliance in donor risk reporting regarding male-to-male sex. Transfusion 2016;56:1899-906.

17. Leeuw ED, de Heer W. Trends in household survey nonresponse: a longitudinal and international comparison. In: Groves RM, Dillman DD, Eltinge JL, et al, editors. Survey nonresponse. New York: Wiley; 2001. p. 41-54.

18. Sheeran P. Intention-behavior relations: a conceptual and empirical review. Eur Rev Soc Psychol 2002;12:1-36.

19. Liszewski W, Becerril J, Terndrup C, et al. The rates, perceptions, and willingness of men who have sex with men to donate blood. Transfusion 2014;54:1733-8 .

20. Slot E, Janssen MP, Marijt-van der Kreek T, et al. Two decades of risk factors and transfusion-transmissible infections in Dutch blood donors. Transfusion 2015;56: 203-14.

\section{SUPPORTING INFORMATION}

Additional Supporting Information may be found in the online version of this article.

Appendix S1. Questionnaire. 